\title{
LEARNing MODEL DEVELOPMENT OF MEMORIZING THE QUR'AN THROUGH INTEGRATION OF INTERNAL AND EXTERNAL REPRESENTATION
}

\author{
Hisban Thaha ${ }^{1)}$, Edhy Rustan ${ }^{2 *}$, Subhan ${ }^{3)}$ \\ 1) IAIN Palopo, Sulawesi Selatan, Indonesia \\ E-mail: hisban.thaha@iainpalopo.ac.id \\ ${ }^{2 *)}$ IAIN Palopo, Sulawesi Selatan, Indonesia \\ E-mail: edhy_rustan@iainpalopo.ac.id \\ 3) IAIN Palopo, Sulawesi Selatan, Indonesia \\ E-mail: subhan_toefl@gmail.com
}

\begin{abstract}
This research aims to create a learning model of memorization of the Qur'an based on the nature of the brain that tends to require relevance between the projection of information that occurred internally in the brain (internal representation) and externally presented information outside the brain (external representation). Integration of the two modes of representation was carried out through a developmental study by adopting Research and Development (R \& D) from Borg and Gall as a reference for the development of conceptual frameworks and memory models of Y Wang as a reference framework of the development of operational stages. From the model development process, several components of the model implementation have successfully been developed. The model implementation was operationally integrated with internal and external representation modes such as Phase I: the formulation of indicators, Phase II diagnostic assessment dealing with prior al-Qur'an memorizing ability, Phase III Conditioning students, Phase IV Coding memorizing materials, and Phase V repetition and recalling memorizing outcomes.
\end{abstract}

Keywords: Memorizing the Qur'an; Integration Model; Internal Representation; External Representation

\section{INTRODUCTION}

Preserving al-Qur'an through memorization has been practiced since the period of the early development of Islam. The preservation method is one of the key instruments applied for the preservation of the existence of Islam that is not only regarded as actualizing religious worships but also delivering the mission of da'wah to form global citizens in the future.

Recently, practitioners of Islamic education began to be engrossed in developing memorization of the Qur'an based on modern scientific perspectives such as Neuroscience and Neurolinguistics (Ahmad, 2014; Al Hafiz et al., 2016; AlZoubi, 2013; Ariffin et al., 2013). As they realized that Neuroscience and Neurolinguistics are the heads of linguistic concepts and memories acting as the core system of the memorization process occurring in the brain.

Both the perspectives of neuroscience and neurolinguistic view memorizing as a cognitive activity that involves the external environment entirely (Franklin \& Zhang, 2014; McLane et al., 2010). The external environment such as linguistic aspects functioning significantly for constructing information, play important roles in occurring mental process in memorization (Kuorikoski \& Ylikoski, 2015). Particularly in the process of projecting the objects of memorizing into concrete information. This is relevant to the nature of the brain that is effectively adaptable to visual information (Sterzer et al., 2014). In this context, it is fundamental to adjust the projection of memorized objects between the internal ongoing process within the brain and the projection of presented information of the external environment.

The projection of internal and external information is recognized as an internal and external presentation (Honey et al., 2017). The former is a projection of information occurring in the Brain while the latest is projected information resented by the external learning environment. External representation is the operationalization of ideas in the form of graphs, diagrams, and tables while internal representation is a cognitive model that a person has in managing and translating information. The models shape the organization and interpretation of information (Gates, 2017). 
Furthermore, from the perspective of the distribution of cognitive operation, the external and internal representation of information are also involved in the processing of information in the brain. Internal representation functions as the neurological medium accommodating the internal human mind, and external representation as external cognitive artifacts as well as time and space as a supporting medium (Zhang \& Patel, 2006). In this case, the internal representation is a mental process (Sheldon \& El-Asmar, 2018) and external representation refers to external cognition that involves environment and experiences (Kizilirmak et al., 2021).

An internal and external representation that are also distribution mediums of cognitive operation can also be found in the study of mathematic psychology. In this discipline, external representation is known as real objects, actual representation, arithmetic symbolic representation, representations of images, and graphs. Meanwhile, the internal representation is known as linguistic representation skill, graph representation skill, and symbolic representation skill (Johnson-laird, 2010). These terminologies can be simply defined that representation as a relationship description between objects and symbols whose real objects are external representation while the mental process defining the objects is internal representation.

Symbolization of objects through the roles of internal and external representation of facilitating the process of information savings into memory is also supported by some research. An external representation can help the brain project information more tangibly as a result the information is stored in memory more rapidly (Kuorikoski \& Ylikoski, 2015). Collaborative research carried out by Zhang \& Patel (2006) revealed that activities needing intense cognitive distribution such as memorizing, require ideal correspondence between an internal and external representation for interpreting information. Similarly, Honey et al. (2017) found that proportional representation between internal and external representation is needed because there are no texts presented by one appropriate representation without assistance from other representation.

Based on the research, the integration between internal and external representation in a model of Qur'an memorizing is required to optimize the process of projecting information in the brain. This is important due to the lack of involvement of theory dealing with internal and external interpretation in teaching Qur'an memorizing. Research of Qur'an memorizing focuses more on developing and finding out memorizing formulation that only involves one of the representations. This results in the abandonment of other representations. For example, Al-Mosallam (2015) only applied the principle of internal representation in developing and implementing the mind map method to enhance memorizing Qur'an skills. Furthermore, Nawaz \& Jahangir (2015) implemented only a single representation as researching silent memorizing method. This principle is also found in other research such as implementing the Sabak, Para Sabak, Ammoktar, and Halaqah Dauri methods (Ariffin et al., 2013) as well as a method of qualitative descriptive learning (Al Hafiz et al., 2016).

Lacking knowledge and researchers' references for the implementation of memorizing applied as a learning model based on the integration of internal and external representation causes the limited alternatives of problemsolving of difficulties in memorizing Qur'an. The Qur'an memorizing methods are particularly suggested for students in Indonesian Islamic Primary Schools because substantially the students are obliged to through school subjects of AlQur'an and Hadist to memorize by competency standards regulated in the school curriculum.

Classical problems dealing with memorizing the Qur'an are, for example, the increasing number of students who find it difficult and burdened to memorize Qur'an. The students experience intense psychological pressure because of lacking interest in out-of-date methods that tend to compel the students to memorize the entire memorized materials by applying conventional methods such as drills, and continuous repetition. Such a situation has a direct systemic impact on several aspects such as lack of motivation and focus, stress, and eventually cause declining students' academic achievement.

Theoretical ideality is based on many facts as elaborated and supported by the reality of revealed difficulties in memorizing Qur'an that has occurred, becomes a substantive foundation for developing a model of learning method of Qur'an memorization based on the integration of internal and external representation. This model is focused on components of procedural development that can be directly implemented by teachers for teaching memorizing Qur'an at the Islamic Primary School level.

\section{METHOD}

This study applies a mixed-method with Research and Development (R\&D) approach. The stages of development can seen in the following figure: 
Phase I. preliminary study and need analysis

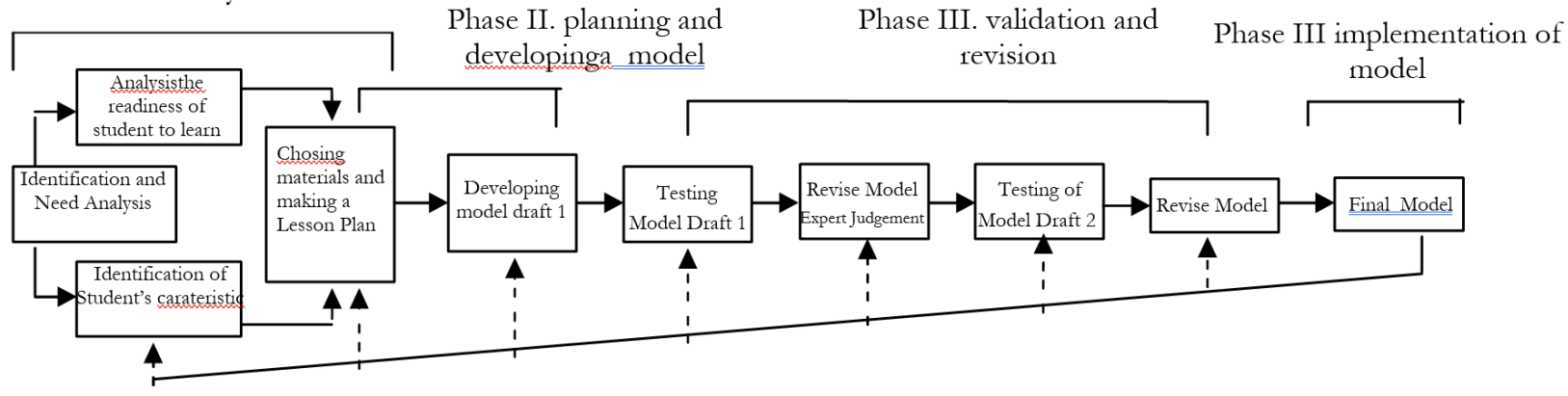

Fig 1. Steps of Learning Model Development of Memorizing the Qur'an Through Integration of Internal and External Representation

Based on the above image, there are nine steps in the process of developing a conceptual model adapted from the instructional design of Dick \& Carey (Dick et al., 2009) and (Gall et al., 2003) modified into 4 stages of development among others (1) phase I preliminary study and need analysis, (2) phase II planning and developing a model, (3) phase III validation and revision, (4) phase IV implementation of models.

The population in this study was the total number of Islamic Primary School students in South Sulawesi. The selected subjects for this study were the second-grade students and teachers of the Qur'an hadith teacher who taught in the classes. Furthermore, the sample was determined by the multi-stage sampling technique, which was to determine the clusters based on the level of accreditation such as A, B, and C. Each cluster represented one school. Thus, secondgrade students from three schools were selected with a simple random technique.

This research used several methods such as questionnaires, need analysis, objective condition, a test of Qur'an memorization ability, and a model validation questionnaire for expert assessment. Need analysis questionnaires and objective conditions were used to collect the students and teachers' needs dealing with the model components and to obtain data of recent conditions of learning Qur'an memorization in the schools. Also, the Qur'an memorization ability test was designed following the theories to measure the achieved level of Qur'an memorization of the students either prior or post-learning. Furthermore, the model validation questionnaires were applied to present empirical and rational assessments on the model by experts of related disciplines such as neuroscience, al-Quran and Hadith, and educational technology. The expert assessment was to ensure the functionality and effectiveness of the model implementation at the school level

\section{RESULT}

This part explores the result of a developed model carried out in four stages such as preliminary study, planning and developing, validating and revising as well as implementation.

\section{A. Preliminary Study and Need Analysis}

Based on the document review, several findings dealing with documenting the implementation of learning Qur'an memorization, such as: Firstly, al-Qur'an Hadith curriculum focused on memorizing al-Qur'an accounted for $56.67 \%$. This indicated that learning memorizing al-Qur'an oriented in interests and nurturing attitude as well as noble characteristics were not enclosed within the instructional documents. Secondly, the document of learning objectives of al-Qur'an memorization accounted for $60.00 \%$. The data revealed that the design of learning was not based on the students' needs. Thirdly, the teaching implementation was $60.00 \%$. The data indicated that the implementation of effective strategies and appropriate methods for teaching Qur'an memorization. Fourthly, time management including program scheduling and design of time allocation distribution accounted for $80.00 \%$, indicating that teaching implementation was appropriate with the determined schedule in the curriculum.

The researchers also conducted interviews with students and teachers of the Koran and Hadith. Data from the interviews revealed that the teachers were still facing difficulties in teaching their students to memorize the given materials, causing the unsatisfactory outcomes of the students memorizing Koran.

The teachers' responses deal with methods to improve the students' the Koran memorization ability revealed that the teachers did not use any special methods or media. Thus, special methods were needed to address Koran memorization-related problems. Concerning the students' responses in the interviews, the data revealed that the students found it difficult to memorize Koran and Hadith. Thus the main problem causing the achievement of learning goals was the improvement of teaching processes, by improving the students' motivations to memorize the Koran.

Furthermore, the result of observation revealed that: Firstly, the teachers' educational and teaching skills gained 
$80.00 \%$ on a category basis. Secondly, the students achieved a score of $80.00 \%$ on the characteristics suitability with the category already unfounded. Third, the learning infrastructure just obtained $60.00 \%$ with less category unfounded. Fourth, in the aspect of the learning process of memorizing the Koran, there were five aspects of the lower categories, namely, mismatch learning measures with the implementation of learning, learning interactions, effectiveness and outcome assessment tools process, convenient learning conditions and support the activities of teaching and learning suitability to increase student competence.

Besides, aspects with medium category consist of 2 aspects including the effectiveness of learning methods and the use of educational media and support. On the other hand, there were 3 aspects with high category including relevance between teaching practices and learning goals, the relevance of learning materials and students' needs, and time efficiency of teaching. Thus, it can be concluded that the process of memorizing the Koran was not effectively carried out.

\section{B. The Planning and the Development of A Model}

Based on the results of preliminary studies which include needing analysis and objective conditions, readiness to learn, as well as the characteristics of students, a procedural model design was compiled. This design integrates internal and external representation by adopting the information transfer in the brain designed by Wu Yuin Hwang (Hwang, Chen, Dung, \& Yang, 2007) to be the basic framework. The stages of the al-Quran memorizing learning can be applied procedurally as follows.

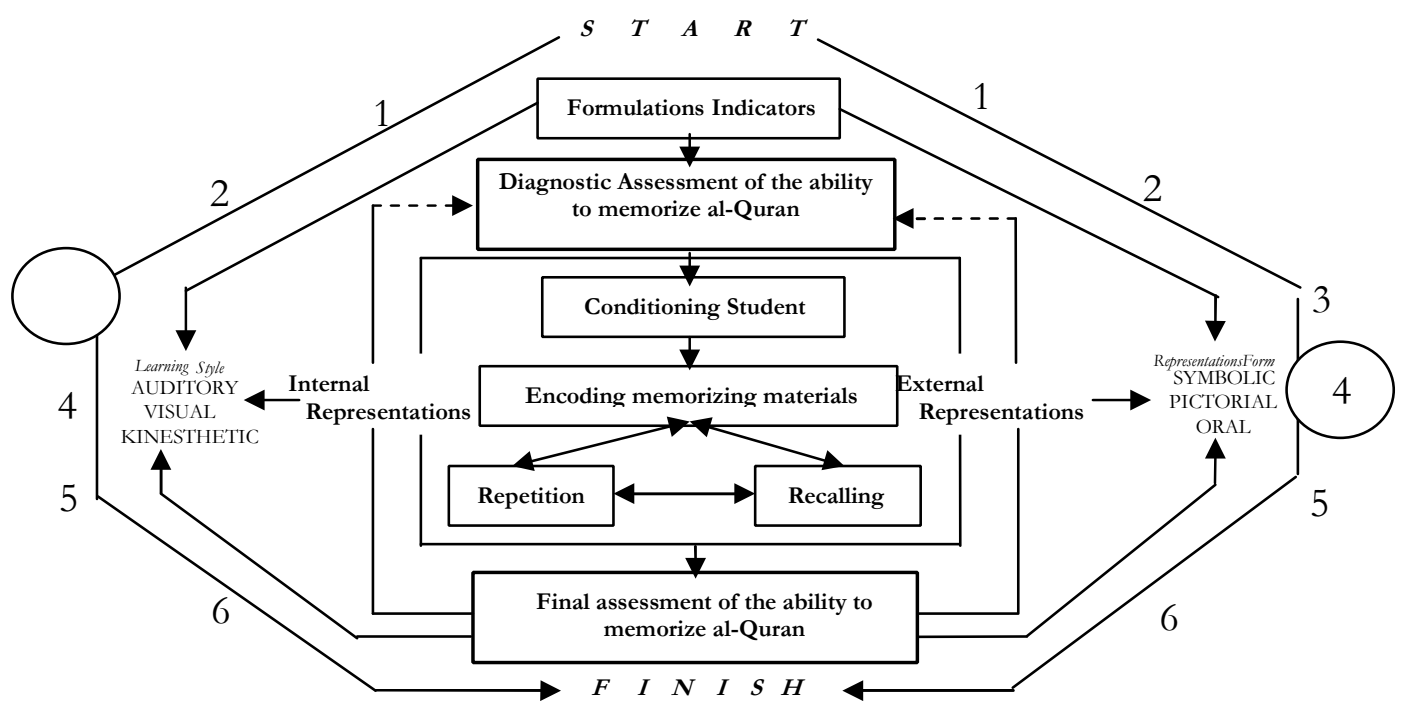

Fig 2. Model of Learning Memorizing the Qur'an by the Integration of Internal and External Representation

Based on Figure 2, the internal and external representations are directly integrated into the conditioning components, encoding, repetition, and recalling. The integration of internal representation is directly integrated with external representation implicitly. Furthermore, the integration is directly stated in the form of learning steps operationally. The operationalization of the model is described as follows.

Phase I Formulation of indicators: at this stage, the teacher determines indicators of the ability to memorize the Qur'an. Formulation of indicators is conditioned to the observation sheet of memorization of Qur'an capability which has been compiled from a variety of relevant theories. These indicators include: (1) Being able to verify (verification) (2) Ability to match (matching) (3) Ability to pair (corresponding) and (4) Ability to read back orally (retrieving) the Qur'an both have previously unknown or being read or listened to.

Phase II Diagnostic Assessment of the ability to memorize al-Quran: at this stage, the teacher assesses performance of the student memorization within observation points on the observation sheet. The results of the observations are then used as a basis to create a general overview as a basis for mapping the overall ability to memorize the Qur'an students. From this, the teacher will be able to identify the extent to which the ability to memorize al-Quran students individually and project for further evaluation.

Phase III Conditioning students: at this stage, the teacher can ensure students' readiness to use the external representation both verbally and visually. The conditioning is done orally through lectures or words of motivation (oral representations) or the stimulus values of kindness through pictures and video display following the actual content of memorized verses (pictorial representations).

Phase IV Encoding memorizing materials: at this stage, students are ready to memorize by reading repetition of the verses of the Qur'an which is the target of memorization. The coding is done by linking verses with images, video, or keywords (keywords) in which an image, a video, or keywords contain values of noble characteristics and wellbeing that exist in the verses. 


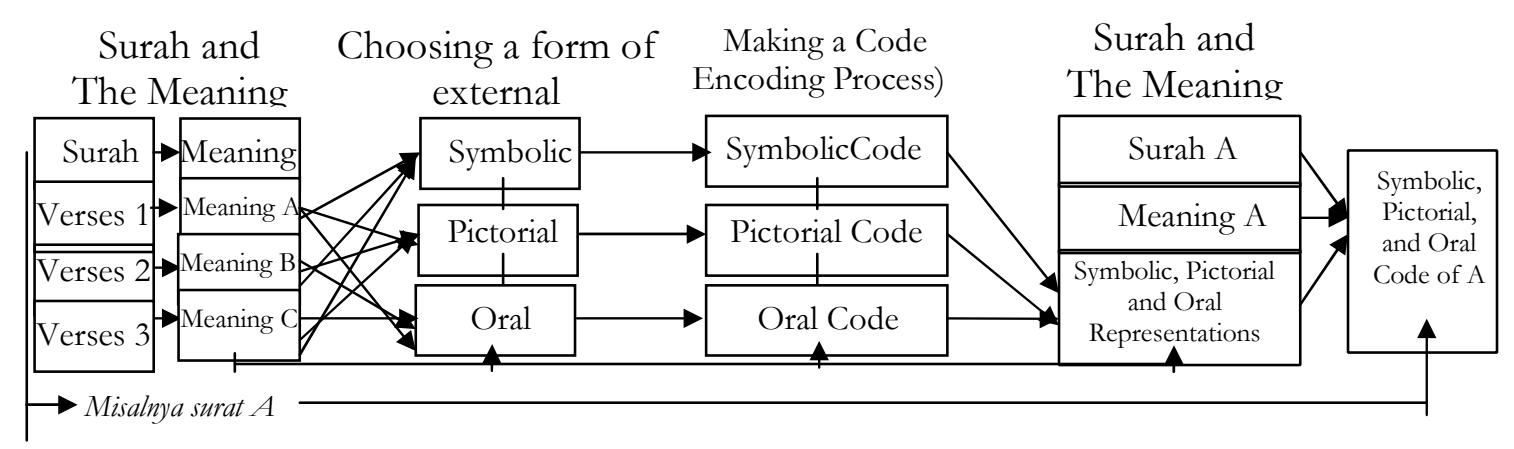

Fig 3. The encoding process on the Learning Model by Integrating Internal and External Representation

Phase V Repetition and recalling the results of memorization: at this stage, the teacher guides the students to repeat and to recall memorizing the material in a structured order. Representation is adjusted to the materials (surah) and the indicator of the ability to memorize the Koran either using verbal representations (words) or visual (pictures or video). This stage is a core phase, in which students should be able to repeat the verses verbally without looking at the Qur'an as a guide.

This phase is the most important step, in which the student is regarded to have memorized after he can fluently recite the verses of the Qur'an as the memorization targets. Recalling is repeated by teachers individually to children using guided instruments (observation sheet) of the ability to memorize the Qur'an that had been developed previously.

Phase VI Final assessment of the ability to memorize alQuran: at this stage, the teacher refers to the points in observation sheets. The improvement of the student's ability can be analyzed by comparing the outcomes of diagnostic assessment and final assessment.

\section{Validation and Revision of the Model}

Expert testing was used to identify the appropriateness of the model applied in learning Qur'an memorization. In this study, researchers such as educational technology experts and experts of the learning Qur'an and hadith were recruited as validators. The result of the validators was explained as follows.

Validation by an expert of technological education: the expert assessed the model's proper validation qualification based on three aspects of the assessment such as content, design, and technical implementation of the model in learning with 200 as a total value. The detail of assessment can be seen as follows:

TABLE 1.

THE RESULTS OF VALIDATION BY EDUCATIONAL TECHNOLOGY EXPERT

\begin{tabular}{ccccc}
\hline $\begin{array}{c}\text { Assessment } \\
\text { Aspect }\end{array}$ & Maximum Score & Score & Percentage & Qualification \\
\hline Content & 100 & 85 & $85 \%$ & Feasible \\
Design & 96 & 72 & $75 \%$ & Feasible \\
Technical & 56 & 43 & $76,79 \%$ & Feasible \\
Score & 252 & 200 & $79,37 \%$ & Feasible \\
\hline
\end{tabular}

Validation by the expert of Qur'an and Hadith: The experts validated the model, design, and technic of application of the model and assessed the model with validation qualification of proper teaching reached a total score of 206. Details of Three aspects of validation can be seen as follows:

TABLE 2.

THE RESULT OF VALIDATION OF QUR'AN AND HADITH TEACHING EXPERTS

\begin{tabular}{ccccc}
\hline Assessment Aspect & Maximum Score & Score & Percentage & Qualification \\
\hline Content & 97 & 81 & $83,51 \%$ & Feasible \\
Design & 96 & 75 & $78,12 \%$ & Feasible \\
Technical & 56 & 50 & $89,29 \%$ & Feasible \\
Score & 249 & 206 & $82,73 \%$ & Feasible \\
\hline
\end{tabular}


Based on the table, the model of Qur'an memorization by the integration of external and internal representation is applicable to improve the ability to memorize Qur'an.

\section{IV.DISCUSSION}

The development of this model has rooted in the discourses that the external environment has an important role in the mental process of memorization (Pande \& Chandrasekharan, 2017). This occurs more particularly in the process of projecting objects of memorization done by the brain that is substantially determined the form of information that appears and is presented in the environment. Thus, the model of memorization is developed for adjustment of the object projection in the brain (Internal representation) and the projection of information presented by the environment (external representation). The development experiences several stages that start from the preliminary study, experiment to the production of a final model that technically applicable in teaching memorizing the Qur'an.

From the procedural perspective, the implementation of this model begins with the formulation of outcome indicators and preliminary skills of Qur'an memorization. Both indicators and assessment are interconnected and based on the instrument of Qur'an memorization ability designed from cognitive theories of memorization: memorizing, recognizing, and recalling. In the next stage, the teacher conditions the students by referring to the principle of the integration of internal and external representation. The conditioning is carried out by instilling the interpretation of Qur'an verses within the external representation. Furthermore, the teacher carries out coding by organizing the verses based on the meanings in the form of external interpretation that is respectively relevant such as symbolic, oral, and pictorial. After coding, the teacher guides the students to practice repeating Qur'an reciting and recalling the reciting without mushaf al- Qur'an.

Internal and external representation in procedural stages of the model implementation is integrated particularly in the stage of conditioning and coding. In the conditioning stage, the wave of the brain of the students has to be directed to the level of alpha and theta wave to position in ideal performance to process and recall information (Rustan, 2017). Likewise, in the process of coding, the materials for memorizing represented internally in the brain must be adjusted with the information represented externally (Honey et al., 2017; Kizilirmak et al., 2021; Pande \& Chandrasekharan, 2017). In this stage, the coding of memorizing is determined based on the appropriateness of representation type applied with the chapter interpretation in general and verses interpretation considering the students' learning styles.

The procedure becomes the excellence that cannot be found in other models. Al-Mosallam 92015) only applies the principle of internal representation through the application of the mind map method to improve students' ability to memorize the Quran. Likewise, the findings of other researchers such as the method of memorizing Qur'an silently (Nawaz \& Jahangir, 2015) that investigated the effectiveness of memorizing Qur'an in silent way, The Sabak, Para Sabak, Ammoktar, and Halaqah Dauri methods (Ariffin et al., 2013), and descriptive qualitative method (Al Hafiz et al., 2016). These Qur'an memorization models tend to emphasize repetition and oral drills that ignore the integration of internal and external representation in the model components.

Furthermore, the implementation of this model influences teachers' teaching methods of Qur'an memorization, for example, teachers have to be precise in the analysis of the student characteristics before teaching Qur'an either individually or classically. It is to understand the need for integration of internal and external representation should follow student learning styles that vary among the students (Muhammad et al., 2020). This is important to optimize the progressivity of memory to save memorizing materials (Sheldon \& El-Asmar, 2018). In other words, teachers have to adapt the orientation of teaching practice of memorizing Qur'an that is initially goal-oriented into a more humanized approach that considers psychological aspects of learning such as happiness, motivation, comfort, and stress.

However, the integration of internal and external representation cannot be explicitly operated in the component of each model. Thus, for the identification of student internal representation, the researchers applied a test of learning style adopted from McWhorter (Muhammad et al., 2020). This is based on theoretical consideration that the processing, organizing, and finally the presentation of information in the brain is determined by student learning styles (Boneva \& Mihova, 2014). This means auditory, visual, and kinesthetic learning styles. The learning style determines methods and information relevant for students to understood and to absorb information when learning. Thus, the internal representation understood as a cognitive model in the brain used to organize and interpret information (Honey et al., 2017; Sheldon \& El-Asmar, 2018). Internal representation regarded as the student learning styles is then used by the researchers to adjust internal and external representation for students to memorize.

Similarly, in the III stage of conditioning students. The researchers cannot ensure if the student's brains are in alphatheta that us productive wave for memorizing (Rustan, 2017). However, the researchers respond by compile suggestive words in religious preaches based on the principles of Neurolinguistics programming (Rustan, 2017). However, to improve the model, next research needs to consider the use of detector of Frequency Following Program (FFG) and a tool to identify neuron interactions when memorizing; such as Magnetic Resonance Imaging (MRI) as applied by Walworth that used MRI based musical therapy to identify brain wave that reflects patient perceptions when having treatment (Walworth, 2010). This is to certainly understand brain wave and neuron activities to optimize the process of conditioning as students are memorizing. 


\section{CONCLUSIONS}

Designing a model of teaching memorizing the Qur'an requires in-depth considering the integration of internal and external representation. This consideration facilitates the nature of the brain that needs a balance between the projection of materials for memorizing and the materials presented in the learning process. Therefore, the progressivity of memory as one of the fundamental elements in memorizing the Qur'an can increase, effective and efficient in the organization and saving information that eventually can improve the ability of students to memorize the Qur'an significantly.

The internal and external representations into the model of Qur'an memorization developed in this research operationally integrated to the conditioning and coding stage. The internal integration is implicit and the external integration is explicit. To comprehend internal representation integration in the stage of conditioning and coding, the researchers utilized a test of learning styles. The results of the test determine and adjust the required external representation. For the integration of external representation in the stage of conditioning, the researchers applied neurolinguistic programming. Furthermore, in the stage of coding, the researchers adjust the meanings of Qur'an verses with appropriate representations by considering student learning styles.

\section{REFERENCES}

Ahmad, K. (2014). Implementation Of Othman Method On Memorization The Quran: A Study In Sulaymaniyyah Institute, Malaysia. Katalog BPS, XXXIII(2), 81-87. https://doi.org/10.1007/s13398-014-0173-7.2

Al-Mosallam, E. A. (2015). Towards Improving Quran Memorization Using Mind Maps. Proceedings - 2013 Taibah University International Conference on Advances in Information Technology for the Holy Quran and Its Sciences, NOORIC 2013, 128-132. https://doi.org/10.1109/NOORIC.2013.36

Al Hafiz, M. M., Yusof, M. F., Ghazali, M. A., \& Md. Sawari, S. S. (2016). Descriptive Qualitative Teaching Method of Memorization in The Institution of Tahfiz Al-Quran Wal Qiraat Pulai Condong and the Students' Level of Academic Excellence. Mediterranean Journal of

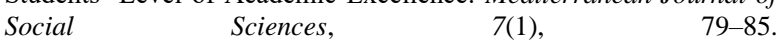
https://doi.org/10.5901/mjss.2016.v7n1s1p79

AlZoubi, A. A. Y. (2013). Use of Information Technology in the Teaching of Quran Recitation (Qira'at) - Electronic Miqrah as a Model. 2013 Taibah University International Conference on Advances in Information Technology for the Holy Quran and Its Sciences, 593621. https://doi.org/10.1109/NOORIC.2013.99

Ariffin, S., Abdullah, M., Suliaman, I., Ahmad, K., Deraman, F., Shah, F. A. Zulkifli, Y., Yusoff, M., Munirah, M., Razzak, A., Murshidi, M., Noor, M., Meftah, J. T., Kasar, A. K., Amir, S., Roslan, M., \& Nor, M. (2013). Effective Techniques of Memorizing the Quran: A Study at Madrasah tahfiz Al-quran, Terengganu, Malaysia. Middle-East Journal of Scientific Research, 13(1), 45-48. https://doi.org/10.5829/idosi.mejsr.2013.13.1.1762

Boneva, D., \& Mihova, E. (2014). Learning Styles and Learning Preferences. Dyslang: Dyslexia and Additional Academic Language Learning, 8.

Dick, W., Carey, L., \& Carey, J. O. (2009). The Systematic Design of Instruction. Longman.

Franklin, A., \& Zhang, J. (2014). Cognitive Considerations for Health Information Technology. In Clinical Decision Support: The Road to Broad Adoption: Second Edition (Second Edi). Elsevier Inc. https://doi.org/10.1016/B978-0-12-398476-0.00022-1
Gall, M. D., Gall, J. P., \& Borg, W. R. (2003). Educational Research An Introduction (A. E. Burvikovs (ed.); 7th ed.). Pearson Education, Inc.

Gates, P. (2017). The Importance of Diagrams, Graphics and Other Visual Representations in STEM Teaching. In STEM Education in the Junior Secondary: The State of Play (STEM Educa, pp. 1-294). Springer Nature Singapore. https://doi.org/10.1007/978-981-105448-8

Honey, C. J., Newman, E. L., \& Schapiro, A. C. (2017). Switching between internal and external modes: A multiscale learning principle. Network Neuroscience, 1(4), 339-356. https://doi.org/10.1162/netn_a_00024

Johnson-laird, P. N. (2010). Mental Models and Human Reasoning. Psichological and Cognitive Science. https://doi.org/https://doi.org/10.1073/pnas.1012933107

Kizilirmak, J. M., Glim, S., Darna, M., \& Khader, P. H. (2021). Selective attention to stimulus representations in perception and memory: commonalities and differences. Psychological Research. https://doi.org/10.1007/s00426-020-01469-Z

Kuorikoski, J., \& Ylikoski, P. (2015). External representations and scientific understanding. $\quad$ Synthese, 192(12), 3817-3837. https://doi.org/10.1007/s11229-014-0591-2

McLane, S., Turley, J. P., Esquivel, A., Engebretson, J., Smith, K. A., Wood, G. L., \& Zhang, J. (2010). Concept analysis of cognitive artifacts. Advances in Nursing Science, 33(4), 352-361. https://doi.org/10.1097/ANS.0b013e3181fb2ed6

Muhammad, B. A., Wu, Z., \& Ahmad, H. K. (2020). A Conceptual Framework for Detecting Learning Style in an Online Education Using Graph Representation Learning. 2020 International Conference on Networking and Network Applications (NaNA), 136140.

Nawaz, N., \& Jahangir, P. D. S. F. (2015). Effects of Memorizing Quran by Heart (Hifz) On Later Academic Achievement. Journal of Islamic $\begin{array}{lll}\text { Studies } & \text { Culture, 3(1), 58-64. }\end{array}$ https://doi.org/10.15640/jisc.v3n1a8

Pande, P., \& Chandrasekharan, S. (2017). Representational competence: towards a distributed and embodied cognition account. Studies in Science Education, 53(1), 1-43. https://doi.org/10.1080/03057267.2017.1248627

Rustan, E. (2017). Learning Creative Writing Model Based on Neurolinguistic Programming. International Journal of Language Education and Culture Review, 3(2), 13-29. https://doi.org/10.21009/IJLECR.032.02

Sheldon, S., \& El-Asmar, N. (2018). The cognitive tools that support mentally constructing event and scene representations. Memory, 26(6), 858-868. https://doi.org/10.1080/09658211.2017.1417440

Sterzer, P., Stein, T., Ludwig, K., Rothkirch, M., \& Hesselmann, G. (2014). Neural processing of visual information under interocular suppression: A critical review. Frontiers in Psychology, 5(MAY), 112. https://doi.org/10.3389/fpsyg.2014.00453

Walworth, D. D. (2010). Effect of live music therapy for patients undergoing magnetic resonance imaging. Journal of Music Therapy, 47(4), 335-350. https://www.ncbi.nlm.nih.gov/pubmed/21488602

Zhang, J., \& Patel, V. L. (2006). Distributed cognition, representation, and affordance. Pragmatics \& Cognition, 14(2), 333-341. https://doi.org/10.1075/pc.14.2.12zha 